Discussion Paper No. 775

\title{
PATENT LICENSING, BARGAINING, AND PRODUCT POSITIONING
}

\author{
Toshihiro Matsumura \\ Noriaki Matsushima
}

May 2010

The Institute of Social and Economic Research Osaka University

6-1 Mihogaoka, Ibaraki, Osaka 567-0047, Japan 


\title{
Patent licensing, bargaining, and product positioning
}

\author{
Toshihiro Matsumura* \\ Institute of Social Science, University of Tokyo \\ Noriaki Matsushima ${ }^{\dagger}$ \\ Institute of Social and Economic Research, Osaka University
}

May 15, 2010

\begin{abstract}
Innovators who have developed advanced technologies, along with launching new products by themselves, often license these technologies to their rivals. When a firm launches a new product, product positioning is also an important matter. Using a standard linear city model with two firms, we investigate how the bargaining power of the licenser affects the product positions of the firms. We find that the inventor more likely chooses the central position when its bargaining power is weak. We also discuss the welfare implication. We find that the inverse $\mathrm{U}$ shape relationship between the bargaining power of the licenser and total social surplus, i.e., neither too strong nor too weak bargaining power of the licensor is optimal.
\end{abstract}

JEL classification: L13, O32, R32

Key words: licensing, oligopoly, R\&D, location, bargaining

*Toshihiro Matsumura, Institute of Social Science, University of Tokyo, 7-3-1, Hongo, Bunkyo, Tokyo, 1130033, Japan. E-mail: matsumur@iss.u-tokyo.ac.jp

$\dagger$ Corresponding author: Noriaki Matsushima, Institute of Social and Economic Research, Osaka University, 6-1 Mihogaoka, Ibaraki, Osaka 567-0047, Japan. Phone: +81-6-6879-8571. Fax: +81-6-6879-8583. E-mail: nmatsush@iser.osaka-u.ac.jp 


\section{Introduction}

Product positioning is an important strategic tool of firms. This influences their decisions on other marketing-mix elements such as pricing, varieties, investments on sales advertising, etc. Due to the difficulties involved in changing one's position, product positioning can be a credible commitment device on decisions and has a high strategic value. Therefore, there are many researches on product positioning decisions (Porter 1980, Hauser and Shugan 1983, Vandenbosch and Weinberg 1995, Kotler 1999, and Sayman, Hoch, and Raju 2002).

Patent licensing is also an important strategic tool of firms and is a fairly common practice that takes place in almost all industries. ${ }^{1}$ When a firm launches new products that contain new concepts and/or technologies, both product positioning of their own products and licensing strategies are important. A typical example is Denso, which is the largest input supplier in Japanese automobile industry. It declared that it will drastically increase licensing revenue from the rivals and engage in $R \& D$ to do so.

Firms launching new products take into account their licensing activities as well as their product positions simultaneously because firms have possibilities to earn additional profits if they sell. In this paper, we try to identify the type of inside innovator that results in a central position (or a peripheral position). To investigate this matter, we employ a standard Hotelling model, which is familiar to many economics and marketing science researchers as a useful tool to analyze product positioning. ${ }^{2}$ We think that our model can be applied to the situation

\footnotetext{
1 Our paper is related to the growing licensing literature in oligopoly. This literature started by Kamien and Tauman $(1984,1986)$ and Katz and Shapiro $(1985,1986)$ who analyzed licensing in standard oligopoly models. Later studies expanded the analysis by considering general two-part tariff policies (Sen and Tauman 2007), models with differentiated goods (Muto 1993, Faulí-Oller and Sandonís 2002), asymmetric information (Gallini and Wright 1990, Beggs 1992), incumbent innovators (Shapiro 1985, Marjit 1990, Wang 1998, Kamien and Tauman 2002), strategic delegation (Mukherjee 2001, Saracho 2002), Stackelberg leadership (Kabiraj 2004, Filippini 2005), moral hazard (Choi 2001), or the integer problem (Sen 2005), etc.

2 The spatial competition model a la Hotelling (1929), considered to be one of the most important oligopoly models, has been viewed by many economics and marketing researchers as an attractive framework for the analysis of product differentiation (see, d'Aspremont et al. (1979), Neven (1985), and Anderson et al. (1992), amongst others). The major advantage of this approach is that it allows for the explicit analysis of product
} 
where a firm produces final products, and also sells key inputs to the rivals. For instance, firms producing liquid crystal displays in the television and cell phone manufacturing industries, hybrid systems in the automobile industry, storage batteries in the computer manufacturing industry, CCDs in the digital camera manufacturing industry sell their products directly and also supply the key inputs to their rivals.

The structure of the model is as follows. Before the game, one inside inventor (firm 1) succeeds in developing a new technology. First, it chooses its product positioning on the Hotelling line. Following this, the rival (firm 2) succeeds in developing an alternative but less efficient technology. However, the advanced (more efficient) technology of firm 1 is protected by a patent; as such, firm 2 cannot use the most efficient technology and produces at a higher cost (or produces a lower quality product). After observing firm 1's positioning, firm 2 chooses its position. Then, firms 1 and 2 negotiate on licensing and engage in Nash bargaining. Finally, they independently choose their prices (Bertrand competition).

We discuss the relationship between the bargaining power of the licenser (firm 1) and its product positioning. We find that strong bargaining power of the licenser distorts the product positioning and reduces total social surplus. When firm 1 has a strong bargaining power, firm 1 locates at the edge of the city so as to mitigate competition and to increase total profits of two firms. As a result, maximal differentiation takes place. When firm 1 has a weaker bargaining power, it tends to choose a position closer to the center so as to reduce the profit of firm 2 at status quo and to improve its bargaining position. Thus, the weaker firm 1's bargaining power, the larger the resulting market share of firm 1 is. The following example can be suitable to our

selection. In line with the spatial competition model, many researchers incorporate various factors into spatial models to investigate the degree of product differentiation. These include consumer distribution (Neven (1986) and Tabuchi and Thisse (1995)), transportation costs (Economides (1986)), demand uncertainty (Casado-Izaga (2000) and Meagher and Zauner (2004)), incomplete information (Boyer et al. (1994) and Boyer et al. (2003)), price regulation (Bhaskar (1997) and Brekke et al. (2006)), mixed oligopoly (Cremer et al. (1991) and Matsumura and Matsushima (2004)), multiple buying (Guo (2006) and Kim and Serfes (2006)), and tournaments (Ganuza and Hauk (2006)). 
model prediction. Toyota is the top runner of hybrid system of automobile and supply rivals this key input. However, Toyota is a poor negotiator and does not obtain sufficient profits from the input supplies. At the same time, Toyota produces main stream products of hybrid cars and chooses the central positioning of product selection rather than maximally differentiating their product from the rivals that purchase the hybrid system from Toyota.

We also discuss the welfare implication. We find that the inverse $U$ shape relationship between the bargaining power of the licenser (firm 1) and total social surplus, i.e., neither too strong nor too weak bargaining power of the licensor is optimal.

We now mention articles related to our paper. Tyagi (2000) examines the product positioning decisions of firms that enter a market sequentially and that have potentially different cost structures. ${ }^{3}$ Meza and Tombak (2009) extended the model of Tyagi (2000). They discuss an asymmetric location-price model with a Hotelling line. They discuss three main topics: (1) endogenous timing of entries (locations), (2) mixed strategies of location, and (3) comparison between the social optimum and equilibrium locations. Based on the model of Meza and Tombak (2009), we allow the efficient firm to license its advanced technology to the inefficient firm. They negotiate the contract term. That is, we add the following concern: the relation between bargaining power and product positioning when an innovator licenses its technology.

The remainder of this paper is organized as follows. Section 2 formulates the model. Sections 3 and 4 present the result without and with licensing, respectively. Section 5 concludes the paper.

\section{The model}

Consider a linear city along the unit interval $[0,1]$, where firm 1 is located at $x_{1}$ and firm 2 is located at $1-x_{2}$. Without loss of generality, we assume that $x_{1} \leq 1-x_{2}$. Consumers are

\footnotetext{
${ }^{3}$ Prescott and Visscher (1977), Neven (1987), and Tabuchi and Thisse (1995) also examine the sequential product positioning decisions of forward-looking firms.
} 
uniformly distributed along the interval. Each consumer buys exactly one unit of the good, which can be produced by either firms 1 or 2 . Let $p_{i}$ denote the price of firm $i(i=1,2)$. The utility of the consumer located at $x$ is given by:

$$
u_{x}= \begin{cases}-t\left(x_{1}-x\right)^{2}-p_{1} & \text { if bought from firm 1, } \\ -t\left(1-x_{2}-x\right)^{2}-p_{2} & \text { if bought from firm 2, }\end{cases}
$$

where $t$ represents the exogenous parameter of the transport cost incurred by the consumer. For a consumer living at $x\left(p_{1}, p_{2}, x_{1}, x_{2}\right)$, where

$$
-t\left(x_{1}-x\left(p_{1}, p_{2}, x_{1}, x_{2}\right)\right)^{2}-p_{1}=-t\left(1-x_{2}-x\left(p_{1}, p_{2}, x_{1}, x_{2}\right)\right)^{2}-p_{2},
$$

the utility is the same whichever of the two firms is chosen. Thus, the demand facing firm 1, $D_{1}$, and that facing firm $2, D_{2}$, are given by:

$$
\begin{aligned}
& D_{1}\left(p_{1}, p_{2}, x_{1}, x_{2}\right)=\min \left\{\max \left(x\left(p_{1}, p_{2}, x_{1}, x_{2}\right), 0\right), 1\right\} \\
& D_{2}\left(p_{1}, p_{2}, x_{1}, x_{2}\right)=1-D_{1}\left(p_{1}, p_{2}, x_{1}, x_{2}\right) .
\end{aligned}
$$

We assume that one of the firms (denoted as firm 1) succeeds in cost-reducing innovation. ${ }^{4}$ Assume that the pre-innovation marginal costs of both firms are $c_{1}=c_{2}=c$. Firm 1's costreducing innovation lowers its marginal cost by $d>0$, so that post-innovation, $c_{1}=c-d$ and $c_{2}=c$.

Firm 1 licenses its new technology to firm 2 at $r q+F$, where $r$ is the royalty rate, $q$ is the quantity supplied by firm 2 , and $F$ is a fixed payment. The total royalty firm 2 pays will depend on the quantity supplied by it using the new technology. The firms' negotiations determine $r$ and $F$. The bargaining procedure is based on generalized Nash bargaining. ${ }^{5}$ The

\footnotetext{
${ }^{4}$ Instead of considering the cost reducing innovation, we can consider the following quality improving innovation. Firm 1 innovates a new product with quality higher than the existing one. This new product increases each consumer's willingness to pay by $d$. This model yields exactly the same location patterns and equilibrium licensing fees as the model with cost-reducing innovation.

${ }^{5}$ An important property of the Nash bargaining solution is that it can be implemented as the outcome of a dynamic non-cooperative alternating-offers bargaining game (Binmore et al., 1986). Moreover, in the literature of management, Brandenburger and Stuart (2007) propose a hybrid noncooperative-cooperative game model, which is called a biform game. Based on those arguments, incorporating Nash bargaining into the Hotelling model is reasonable.
} 
degree of firm 1's bargaining power is $\beta(1 / 2 \leq \beta<1)$. That is, the licenser has equal or stronger bargaining power than the licensee. Under licensing, the marginal cost of production of firm 1 is $c-d$ and that of firm 2 is $c-d+r$. The royalty satisfies $r \leq d$; otherwise, firm 2 never uses the technology of firm 1 even after accepting the licensing contract. ${ }^{6}$

The game runs as follows. In the first stage, firm 1 choose its location $x_{1} \in[0,1 / 2]$ (by symmetry, $x_{1} \geq 1 / 2$ is equivalent to $\left.1-x_{1}(\leq 1 / 2)\right)$. Observing the location of firm 1 , firm 2 chooses its location $x_{2} \in[0,1] .^{7}$ In the second stage, $r$ and $F$ are determined by the negotiations between the firms. In the third stage, each firm $i(i=1.2)$ chooses its price $p_{i} \in\left[c_{i}, \infty\right)$ independently. ${ }^{8}$

\section{No-licensing case}

In this section, we discuss the case where the innovator (firm 1) does not license its advanced technology as a benchmark. We discuss licensing explicitly in the next section.

Without licensing, the profit functions of the firms are as follows:

$$
\pi_{1}^{N}=\left(p_{1}-(c-d)\right) D_{1}\left(x_{1}, x_{2}, p_{1}, p_{2}\right), \quad \pi_{2}^{N}=\left(p_{2}-c\right) D_{2}\left(x_{1}, x_{2}, p_{1}, p_{2}\right)
$$

where superscript $N$ indicates the no licensing case.

First, we investigate the price competition stage. Given the locations of firms $x_{1}$ and $x_{2}$, firms face Bertrand competition. The equilibrium prices are as follows:

$$
p_{1}^{N}= \begin{cases}c-t\left(1-x_{1}-x_{2}\right)\left(1-x_{1}+x_{2}\right) & \text { if } d \geq t\left(1-x_{1}-x_{2}\right)\left(3-x_{1}+x_{2}\right), \\ \frac{3 c-2 d+t\left(1-x_{1}-x_{2}\right)\left(3+x_{1}-x_{2}\right)}{3} & \text { if } d<t\left(1-x_{1}-x_{2}\right)\left(3-x_{1}+x_{2}\right),\end{cases}
$$

\footnotetext{
${ }^{6}$ Even though firm 2 accepted a contract term with $r>d$, it would not use the licensing technology because it is more expensive to using its own less efficient technology. Anticipating the action of firm 2, firm 1 recognizes that the marginal cost of firm 2 remains $c-d$. This outcome is similar to that in which firm 2 rejects the licensing offer. This is equivalent to the no-licensing case in Section 3.

${ }^{7}$ Meza and Tombak (2009) show that the efficient firm first chooses its location and then the inefficient firm does when the timing of the locations is endogenously determined. Their result supports the timing structure employed in this paper.

${ }^{8}$ Choosing $p_{i}<c_{i}$ is weakly dominated by choosing $p_{i}=c_{i}$; hence, we assume that the lower bound of the price is its cost.
} 


$$
p_{2}^{N}= \begin{cases}c & \text { if } d \geq t\left(1-x_{1}-x_{2}\right)\left(3-x_{1}+x_{2}\right), \\ \frac{3 c-d+t\left(1-x_{1}-x_{2}\right)\left(3-x_{1}+x_{2}\right)}{3} & \text { if } d<t\left(1-x_{1}-x_{2}\right)\left(3-x_{1}+x_{2}\right) .\end{cases}
$$

If $d \geq t\left(1-x_{1}-x_{2}\right)\left(3-x_{1}+x_{2}\right), D_{1}=1$ and $D_{2}=0$ (monopoly by firm 1 with firm 2 only serving as a potential competitor). If $d<t\left(1-x_{1}-x_{2}\right)\left(3-x_{1}+x_{2}\right), D_{1}>0, D_{2}>0$ (both firms produce in the market).

The resulting profits of the firms are as follows:

$$
\begin{aligned}
& \pi_{1}^{N}= \begin{cases}d-t\left(1-x_{1}-x_{2}\right)\left(1-x_{1}+x_{2}\right) & \text { if } d \geq t\left(1-x_{1}-x_{2}\right)\left(3-x_{1}+x_{2}\right), \\
\frac{\left(d+t\left(1-x_{1}-x_{2}\right)\left(3+x_{1}-x_{2}\right)\right)^{2}}{18 t\left(1-x_{1}-x_{2}\right)} & \text { if } d<t\left(1-x_{1}-x_{2}\right)\left(3-x_{1}+x_{2}\right),\end{cases} \\
& \pi_{2}^{N}= \begin{cases}0 & \text { if } d \geq t\left(1-x_{1}-x_{2}\right)\left(3-x_{1}+x_{2}\right), \\
\frac{\left(t\left(1-x_{1}-x_{2}\right)\left(3-x_{1}+x_{2}\right)-d\right)^{2}}{18 t\left(1-x_{1}-x_{2}\right)} & \text { if } d<t\left(1-x_{1}-x_{2}\right)\left(3-x_{1}+x_{2}\right) .\end{cases}
\end{aligned}
$$

Second, we consider the location choice of firm 2. Given the location of firm $1 x_{1}$, firm 2 decides its location. ${ }^{9}$

Lemma 1 For any $x_{1}(\leq 1 / 2)$, the optimal location of firm 2 is 1 ( $\left.x_{2}=0\right)$.

As pointed out by d'Aspremont et al. (1979), to mitigate price competition, firm 2 maximizes the degree of product differentiation given the location of firm 1.

Third, we consider the location choice of firm 1. After several calculations, we have the following lemma:

Lemma 2 (Meza and Tombak (2009, p.692)) When the locations are sequentially determined, the optimal location of firm 1 is

$$
x_{1}= \begin{cases}0 & \text { if } d \leq t, \\ \frac{t-\sqrt{(4 t-3 d) t}}{3 t} & \text { if } t<d \leq \frac{(29 \sqrt{145}-187) t}{128} \simeq 1.267 t \\ \frac{1}{2} & \text { if } \frac{(29 \sqrt{145}-187) t}{128} \leq d .\end{cases}
$$

\footnotetext{
${ }^{9}$ Note that, if $d>t\left(1-x_{1}\right)\left(3-x_{1}\right)$, it is indifferent for firm 2 to choose any location.
} 


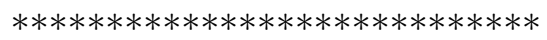

Figure 1 here

Lemma 2 states that $x_{1}$ is increasing in $d$. A stronger advantage of firm 1 makes its location closer to the center. This result suggests that the stronger firm is more likely to choose a central position when it does not license its advanced technology.

We briefly mention the mechanism of the result. When cost asymmetry is not significant, a similar strategic interaction in d'Aspremont et al. (1979) works. Mitigating price competition between the firms is important for them and the products are maximally differentiated. When cost asymmetry of the firms is significant, the price effect does not work. As pointed out by Ziss (1993), when the cost asymmetry is significant, the optimal location of the efficient firm is the same as that chosen by the inefficient firm because monopolizing the market is the best choice for the efficient firm. ${ }^{10}$ The mechanism described by Ziss (1993) works in our model. The follower chooses the location as far as possible from the location of the leader. Thus, if the cost advantage is significant, the leader chooses the center position so as to minimize the resulting differentiation.

\section{Licensing case}

We consider the model where there is bargaining over licensing. We provide three stages to derive the equilibrium outcomes: (1) pricing stage, (2) licensing stage, and (3) location stage.

First, consider the pricing stage. Under the licensing contract, the profits of the firms are as follows:

$$
\begin{aligned}
\pi_{1}^{L} & =\left(p_{1}-(c-d)\right) D_{1}+r D_{2}+F \\
& =\left(p_{1}-(c-d)\right) D_{1}+r\left(1-D_{1}\right)+F
\end{aligned}
$$

\footnotetext{
${ }^{10}$ If the efficient firm locates at a different point, to monopolize the market it must set its price as $c_{2}-\alpha(\alpha$ depends on the distance between the firms).
} 


$$
\begin{aligned}
& =\left(p_{1}-(c-d)-r\right) D_{1}+r+F \\
\pi_{2}^{L} & =\left(p_{2}-(c-d)-r\right) D_{2}-F .
\end{aligned}
$$

Consider the price competition at the last stage. The first-order conditions lead to the following:

$$
\begin{aligned}
& p_{1}=(c+r-d)+\frac{t\left(1-x_{1}-x_{2}\right)\left(3+x_{1}-x_{2}\right)}{3} \\
& p_{2}=(c+r-d)+\frac{t\left(1-x_{1}-x_{2}\right)\left(3-x_{1}+x_{2}\right)}{3} .
\end{aligned}
$$

Substituting the prices into the profit functions in (7) and (8), we have

$$
\begin{aligned}
& \pi_{1}^{L}=\frac{t\left(1-x_{1}-x_{2}\right)\left(3+x_{1}-x_{2}\right)^{2}}{18}+r+F, \\
& \pi_{2}^{L}=\frac{t\left(1-x_{1}-x_{2}\right)\left(3-x_{1}+x_{2}\right)^{2}}{18}-F .
\end{aligned}
$$

Note that the profit functions of the firms are similar to those in d'Aspremont et al. (1979) except for the second and third terms $(r+F$ and $-F)$. When firm 1 licenses its advanced technology, per unit licensing fee $r$ acts as an opportunity cost of firm 1 . If firm 1 decreases its price, the quantity supplied by it increases but the payment by firm 2 decreases. Therefore, this licensing case is similar to the competition between two symmetric firms (see (7) and (8)). If $r$ and $F$ were exogenously given, maximum differentiation would appear $\left(x_{1}=x_{2}=0\right)$ and then the joint profit would be maximized in equilibrium (Matsumura et al. (2010)). As mentioned later, when the firms negotiate with each other, this prediction does not always hold.

Next, consider the licensing stage. The firms negotiate the levels of $r$ and $F$. The negotiation process is based on generalized Nash bargaining. In the model, the process is described as follows:

$$
\max _{r, F} \beta \log \left[\pi_{1}^{L}-\pi_{1}^{N}\right]+(1-\beta) \log \left[\pi_{2}^{L}-\pi_{2}^{N}\right]
$$

where $\pi_{i}^{L}$ is the profit of firm $i(i=1,2)$ when firm 1 licenses its technology and $\pi_{i}^{N}$ is the profit of firm $i(i=1,2)$ in which firm 1 does not. As mentioned in the previous section, we have to consider two cases: (i) $d<t\left(1-x_{1}-x_{2}\right)\left(3-x_{1}+x_{2}\right)$; (ii) $d \geq t\left(1-x_{1}-x_{2}\right)\left(3-x_{1}+x_{2}\right)$. 
Using (4), (5), (9), and (10), we solve the maximization problem in (11). ${ }^{11}$ In the maximization problem, only $\pi_{1}^{L}$ includes $r$. $\pi_{1}^{L}$ is monotonically increasing in $r$ (see (9)). Since $r \leq d$, we have the following lemma:

Lemma 3 In any case, $r=d$. $F$ is given by

$$
F=\left\{\begin{array}{c}
\frac{d\left[2\left(1-x_{1}-x_{2}\right)\left(3(3 \beta-2)-(2 \beta-1)\left(x_{1}-x_{2}\right)\right) t-(2 \beta-1) d\right]}{18 t\left(1-x_{1}-x_{2}\right)} \\
\text { if } d<t\left(1-x_{1}-x_{2}\right)\left(3-x_{1}+x_{2}\right), \\
\frac{\left(1-x_{1}-x_{2}\right)\left(3-x_{1}+x_{2}\right)\left(3(4 \beta-3)-(2 \beta-1)\left(x_{1}-x_{2}\right)\right) t}{18} \\
\text { if } d \geq t\left(1-x_{1}-x_{2}\right)\left(3-x_{1}+x_{2}\right) .
\end{array}\right.
$$

To understand how the locations of the firms affect the bargaining solution in (11), we examine the relation between fixed payment $F$ and the locations of the firms. Differentiating $F$ with respect to $x_{1}$, we have

$$
\frac{\partial F}{\partial x_{1}}=\left\{\begin{array}{rr}
-\frac{d(2 \beta-1)\left(2 t\left(1-x_{1}-x_{2}\right)^{2}+d\right)}{18 t\left(1-x_{1}-x_{2}\right)^{2}} \quad \text { if } d<t\left(1-x_{1}-x_{2}\right)\left(3-x_{1}+x_{2}\right), \\
-\frac{t(2 \beta-1) x_{2}\left(2-2 x_{1}-x_{2}\right)}{18}+\frac{t\left(39-26 x_{1}+3 x_{1}^{2}-2\left(27-20 x_{1}+3 x_{1}^{2}\right) \beta\right)}{18} \\
\text { if } d \geq t\left(1-x_{1}-x_{2}\right)\left(3-x_{1}+x_{2}\right),
\end{array}\right.
$$

As shown in the following Lemma $4, x_{2}=0$ in equilibrium, that is, firm 2 prefers maximum differentiation given the location of firm 1 . Substituting $x_{2}=0$ into the partial derivative, we have

$$
\left.\frac{\partial F}{\partial x_{1}}\right|_{x_{2}=0}= \begin{cases}-\frac{d(2 \beta-1)\left(2 t\left(1-x_{1}\right)^{2}+d\right)}{18 t\left(1-x_{1}\right)^{2}} & \text { if } d<t\left(1-x_{1}\right)\left(3-x_{1}\right), \\ \frac{t\left(39-26 x_{1}+3 x_{1}^{2}-2\left(27-20 x_{1}+3 x_{1}^{2}\right) \beta\right)}{18} & \text { if } d \geq t\left(1-x_{1}\right)\left(3-x_{1}\right) .\end{cases}
$$

Note that the second value in (14) is always positive (negative) if $\beta<13 / 18 \simeq 0.722(\beta=1)$.

\footnotetext{
${ }^{11}$ The inequality, $\pi_{1}^{L} \leq \pi_{1}^{N}$, never appear in the maximization problem because $\log \left[\pi_{1}^{L}-\pi_{1}^{N}\right]$ does not have a value. In other words, the inequality $\pi_{1}^{L}>\pi_{1}^{N}$ must be hold. That is, firm 1 always has an incentive to license its technology.
} 
From the partial derivative, we find that when the cost difference between the firms is significant and the bargaining power of firm 1 is weak, moving toward the center can increase the fixed payment for firm 1. We explain the intuition. We consider the threat point of the bargaining (competitive profits without licensing). As mentioned in the previous section, when the cost asymmetry $d$ is large, as the degree of product differentiation decreases, the non licensing profit of firm 1 can increase while that of firm 2 certainly decreases. Therefore, a decrease in the degree of product differentiation can enhance the bargaining position of firm 1 . Now, we add explanations about the partial derivative mentioned above. When the bargaining power of firm 1 is weak, firm 1 cannot fully extract the benefit of licensing from firm 2 through the fixed fee, $F$. As mentioned earlier (see the discussion after equations (9) and (10)), since per unit licensing fee $r$ acts as an opportunity cost of firm 1, firm 1 does not have to deprive the demand of firm 2. The benefit of licensing is caused by the mitigation of competition between the firms. The direct benefit is maximized when the firms maximally differentiate their products. Through the negotiation, firm 1 (partially) extracts the direct benefit. When firm 1 has weaker bargaining power, the diminish in the threat point of firm 2 is more important than the direct benefit because the direct benefit is small. The partial derivative of $F$ reflects this fact.

Third, we consider the location choice of firm 2. Given the location of firm $1, x_{1}$, firm 2 decides its location $x_{2}$. Using (10) and $F$ in (12), we solve the maximization problem of firm 2 and then we have

Lemma 4 For any $x_{1}(\leq 1 / 2)$, the optimal location of firm 2 is $1\left(x_{2}=0\right)$.

Finally, we consider the location choice by firm 1. Using (9) and $F$ in (12), we solve the maximization problem of firm 1. The following proposition states the equilibrium location of firm 1. This indicates that $x_{1}$ is decreasing in $\beta$, that is, as the bargaining power of firm 1 becomes weak, its location choice tends to the center. 
Proposition 1 With licensing, the equilibrium location of firm 1 is as follows:

$$
x_{1}= \begin{cases}\frac{1}{2} & \text { if } \frac{1}{2} \leq \beta \leq \frac{36}{71} \text { and } d \geq d_{a}(\beta) t, \\ \frac{-9+10 \beta+\sqrt{81-126 \beta+19 \beta^{2}}}{3 \beta} & \text { if } \frac{36}{71} \leq \beta \leq \frac{2}{3} \text { and } d \geq d_{b}(\beta) t, \\ 0 & \text { otherwise. }\end{cases}
$$

where

$$
\begin{aligned}
& d_{a}(\beta) \equiv \frac{6(3 \beta-2)+\sqrt{90-269 \beta+214 \beta^{2}}}{2(2 \beta-1)}, \\
& d_{b}(\beta) \equiv \frac{\left.27 \beta(3 \beta-2)+\sqrt{3\left(1963 \beta^{4}+5026 \beta^{3}-16551 \beta^{2}+12636 \beta-2916-4(2 \beta-1)\left(81-216 \beta+19 \beta^{2}\right)^{3 / 2}\right.}\right)}{9 \beta(2 \beta-1)} . \\
& * * * * * * * * * * * * * * * * * * * * * * * * * * * *
\end{aligned}
$$

Figures $2 \mathrm{a}$ and $2 \mathrm{~b}$ here

Proposition 1 states that with licensing, $x_{1}$ is decreasing or non-increasing in $\beta$ when $d$ is large enough. This result indicates that firm 1's (the inventor's) location choice tends to the center when its bargaining power is weaker. These results show that a cost advantage and bargaining power have different implications for product positioning.

We now briefly mention the mechanism of the result. When firm 1 licenses its technology, joint profit is maximized if the firms maximally differentiate their products. Firm 1 earns an additional profit through fixed payment $F$, which depends on the bargaining power. If firm 1's bargaining power is weak, increasing the degree of product differentiation has two effects. One, there is an increase in the profit through price competition (per unit payment $r$ ) and two, there is a decrease in the profit through fixed payment. Firm 1 has to balance two contrary effects. This yields our Proposition 1.

We now briefly discuss the welfare implication. There is an inverted $U$ relationship between bargaining power $\beta$ and social surplus. In this setting, both firms have the same marginal cost, and the price competition between the firms is similar to that in d'Aspremont et al. (1979). 
Given the locations of the firms $\left(x_{1}\right.$ and $\left.x_{2}=0\right)$, the indifference consumer $x^{*}$ and the total transport costs $T C$ are as follows:

$$
\begin{aligned}
x^{*}=\frac{3+x_{1}}{6}, \quad T C & =\int_{0}^{x_{1}}\left(x_{1}-x\right)^{2} d x+\int_{x_{1}}^{x^{*}}\left(x-x_{1}\right)^{2} d x+\int_{x^{*}}^{1}(1-x)^{2} d x \\
& =\frac{3-9 x_{1}+13 x_{1}^{2}+5 x_{1}^{3}}{36} .
\end{aligned}
$$

On the domain $[0,1 / 2], T C$ is a convex function and minimized at $x_{1}=(4 \sqrt{19}-13) / 15 \simeq$ 0.2957. That is, social surplus $-T C$ is maximized when $x_{1}=(4 \sqrt{19}-13) / 15$. As mentioned earlier, there is an inverse relationship between $\beta$ and $x_{1}$ (when $d$ is large, as the value of $\beta$ increases, the value of $x_{1}$ decreases). When $\beta=1 / 2(\beta=1), x_{1}=1 / 2\left(x_{1}=0\right)$. Therefore, there is an inverted $U$ relationship between bargaining power $\beta$ and social surplus.

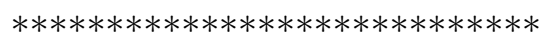

Figure 3 here

\section{Concluding remarks}

We have investigated the relationship between licensing activities and equilibrium locations in a product differentiation model. We formulate a model where both the innovator (licenser) and the licensee produce. We take into account a bargaining procedure between the licenser and the licensee. Without licensing, the degree of the cost advantage of the licenser affects its positioning; a stronger cost advantage results in a more central positioning. With licensing, the degree of the cost advantage of the licenser does not affect its positioning; however, its bargaining power over the licensee does have an effect on the positioning. A weaker bargaining power results in a more central positioning.

In this paper, we restrict our attentions to the post-innovation stage and focus on the product positioning. The bargaining power of the inventors affects innovation activities and thus affects welfare. This is left for future research. 


\section{Appendix}

Proof of Lemma 1: Suppose that $d \leq t\left(1-x_{1}\right)\left(3-x_{1}\right)$. Differentiating $\pi_{2}^{N}$ with respect to $x_{2}$, we have

$$
\frac{\partial \pi_{2}^{N}}{\partial x_{2}}=-\frac{\left(t\left(1-x_{1}-x_{2}\right)\left(3-x_{1}+x_{2}\right)-d\right)\left(t\left(1-x_{1}-x_{2}\right)\left(5-3 x_{1}-x_{2}\right)+d\right)}{18 t\left(1-x_{1}-x_{2}\right)^{2}}<0 .
$$

Therefore, $x_{2}=0$ is optimal. Suppose that $d>t\left(1-x_{1}\right)\left(3-x_{1}\right)$. Any $x_{2}$ yields zero profits of firm 2, thus any location can be optimal for firm 2 .

Q.E.D.

Proof of Lemma 4: The first-order condition of firm 2 is

$$
\frac{\partial \pi_{2}}{\partial x_{2}}=\left\{\begin{array}{r}
\frac{-\left(1-x_{1}-x_{2}\right)^{2}\left(3-x_{1}+x_{2}\right)\left(1+x_{1}+3 x_{2}\right) t^{2}}{18 t\left(1-x_{1}-x_{2}\right)^{2}} \\
+\frac{d(2 \beta-1)\left(d-2\left(1-x_{1}-x_{2}\right)^{2} t\right)}{18 t\left(1-x_{1}-x_{2}\right)^{2}} \\
\text { if } d<t\left(1-x_{1}-x_{2}\right)\left(3-x_{1}+x_{2}\right), \\
-\frac{t\left(9+x_{1}\left(2-x_{1}\right)+2 x_{2}\left(8-x_{1}\right)+3 x_{2}^{2}\right)(1-\beta)}{9}<0 \\
\text { if } d \geq t\left(1-x_{1}-x_{2}\right)\left(3-x_{1}+x_{2}\right) .
\end{array}\right.
$$

We now show that the first value is also negative. When $d=t\left(1-x_{1}-x_{2}\right)\left(3-x_{1}+x_{2}\right)$, the former part is maximized and then its value is given by:

$$
\left.\frac{\partial \pi_{2}}{\partial x_{2}}\right|_{d=t\left(1-x_{1}-x_{2}\right)\left(3-x_{1}+x_{2}\right)}=-\frac{t\left(3-x_{1}+x_{2}\right)\left(1+x_{1}+3 x_{2}\right)(1-\beta)}{9}<0 .
$$

Therefore, $x_{2}=0$ is the optimal choice of firm 2 .

Q.E.D.

Proof of Proposition 1: First, we derive the local optimal location of firm 1 under the two cases: $(1) d<t\left(1-x_{1}-x_{2}\right)\left(3-x_{1}+x_{2}\right)$ and $(2) d \geq t\left(1-x_{1}-x_{2}\right)\left(3-x_{1}+x_{2}\right)$. Second, we compare the two optimal locations and show the global optimal location of firm 1.

We consider the case where $d<t\left(1-x_{1}-x_{2}\right)\left(3-x_{1}+x_{2}\right)$. Given the reaction of firm 2 $\left(x_{2}=0\right)$, the first-order condition of firm 1 is:

$$
\frac{\partial \pi_{1}}{\partial x_{1}}=-\frac{\left(1-x_{1}\right)^{2}\left(3+x_{1}\right)\left(1+3 x_{1}\right)+d(2 \beta-1)\left(d+2\left(1-x_{1}\right)^{2}\right)}{18\left(1-x_{1}\right)^{2}}<0 .
$$


When $d<t\left(1-x_{1}-x_{2}\right)\left(3-x_{1}+x_{2}\right), x_{1}=0$ is the local optimal location of firm 1 . The profit of firm 1 is:

$$
\pi_{1 A} \equiv \frac{9 t^{2}+6 t d(1+3 \beta)+d^{2}(1-2 \beta)}{18 t}
$$

We consider the case where $d \geq t\left(1-x_{1}-x_{2}\right)\left(3-x_{1}+x_{2}\right)$. Given the reaction of firm 2 $\left(x_{2}=0\right)$, the first-order condition of firm 1 is:

$$
\frac{\partial \pi_{1}}{\partial x_{1}}=\frac{t\left(9(2-3 \beta)-2(9-19 \beta) x_{1}-3 \beta x_{1}^{2}\right)}{9} .
$$

If $\beta \geq 2 / 3$, this is always negative and the local optimal location for firm 1 is $x_{1}=0$. ¿From the equation $\partial \pi_{1} / \partial x_{1}=0$, we have a candidate of the local optimal location:

$$
x_{1}=\frac{-9+10 \beta+\sqrt{81-126 \beta+19 \beta^{2}}}{3 \beta} .
$$

From a simple calculation, we find that this is larger than $1 / 2$ if $\beta<36 / 71$. We can summarize these calculations as follows:

$$
x_{1}= \begin{cases}\frac{1}{2} & \text { if } \frac{1}{2} \leq \beta \leq \frac{36}{71}, \\ \frac{-9+10 \beta+\sqrt{81-126 \beta+19 \beta^{2}}}{3 \beta} & \text { if } \frac{36}{71} \leq \beta \leq \frac{2}{3} \\ 0 & \text { if } \frac{2}{3} \leq \beta .\end{cases}
$$

We have to derive the condition that $x_{1}$ in each case satisfies the inequality $d \geq t\left(1-x_{1}-\right.$ $\left.x_{2}\right)\left(3-x_{1}+x_{2}\right)=\left(1-x_{1}\right)\left(3-x_{1}\right)$. Substituting $x_{1}$ into the inequality, we have

$$
x_{1}= \begin{cases}\frac{1}{2} & \text { if } \frac{1}{2} \leq \beta \leq \frac{36}{71} \text { and } d \geq \frac{5}{4} \\ \frac{-9+10 \beta+\sqrt{81-126 \beta+19 \beta^{2}}}{3 \beta} & \text { if } \frac{36}{71} \leq \beta \leq \frac{2}{3}, \text { and } \\ & d \geq \frac{2\left(81-99 \beta+13 \beta^{2}-(9-4 \beta) \sqrt{81-126 \beta+19 \beta^{2}}\right)}{9 \beta^{2}}, \\ 0 & \text { if } \frac{2}{3} \leq \beta \text { and } d \geq 3 .\end{cases}
$$

If the condition is not satisfied in each case, the local optimal location is the corner solution that is inferior to the local optimal location $\left(x_{1}=0\right)$ in the former case $\left(d<t\left(1-x_{1}-x_{2}\right)(3-\right.$ 
$\left.\left.x_{1}+x_{2}\right)=\left(1-x_{1}\right)\left(3-x_{1}\right)\right)$. The profit of firm 1 is:

$$
\pi_{1 B} \equiv \begin{cases}d+\frac{(55 \beta-18) t}{72} & \text { if } x_{1}=\frac{1}{2}, \\ d+\frac{2(7 \beta-9)\left(81-126 \beta+4 \beta^{2}\right) t}{243 \beta^{2}} & \text { if } x_{1}=\frac{-9+10 \beta+\sqrt{81-126 \beta+19 \beta^{2}}}{3 \beta} . \\ +\frac{2\left(81-126 \beta+19 \beta^{2}\right)^{3 / 2} t}{243 \beta^{2}} & \end{cases}
$$

Finally, we compare the two local optimal locations. Comparing $\pi_{1 A}$ with $\pi_{1 B}$, we have Proposition 1.

Q.E.D. 


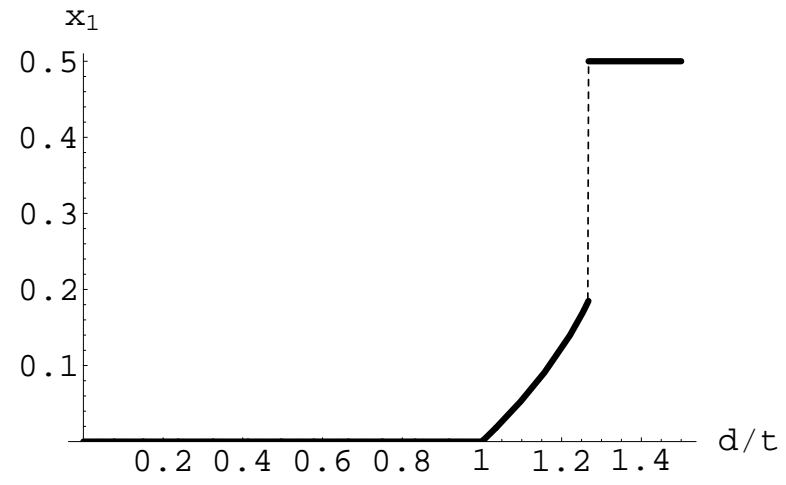

Figure 1: The optimal location of firm 1

Horizontal: $d$, Vertical: $x_{1}$ 


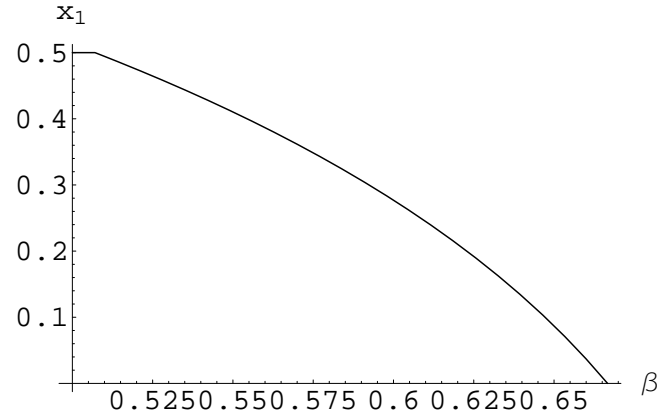

Figure 2a: The location of firm 1 Horizontal: $\beta$, Vertical: $x_{1}$

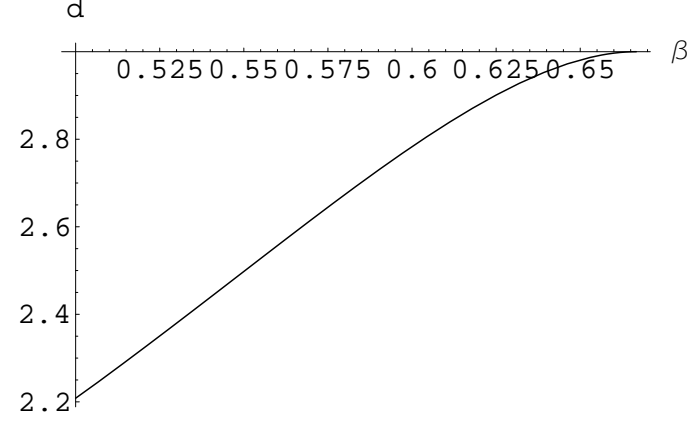

Figure 2b: $d_{a}(\beta)$ and $d_{b}(\beta)$

Horizontal: $\beta$, Vertical: $d(\cdot)$. 


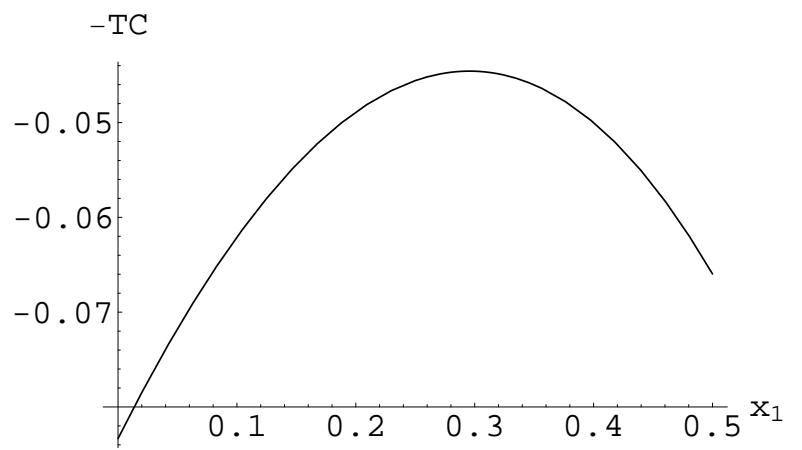

Figure 3: The relation between $x_{1}$ and $T C$

Horizontal: $x_{1}$, Vertical: $S W=-T C$ 


\section{References}

Anderson, S. P., A. de Palma, and J.-F. Thisse, 1992, Discrete Choice Theory of Product Differentiation. Cambridge, MA: MIT Press.

Beggs, A.W., 1992, "The Licensing of Patents under Asymmetric Information," International Journal of Industrial Organization, 10(2), 171-191.

Bhaskar, V., 1997, "The Competitive Effects of Price-Floors," Journal of Industrial Economics, 45(3), 329-340.

Binmore, K., A. Rubinstein, A. Wolinsky, 1986, "The Nash Bargaining Solution in Economic Modelling," RAND Journal of Economics 17(2), 176-188.

Boyer, M., J.-J. Laffont, P. Mahenc, and M. Moreaux, 1994, "Location Distortions under Incomplete Information," Regional Science and Urban Economics, 24(4), 409-440.

Boyer, M., P. Mahenc, and M. Moreaux, 2003, "Asymmetric Information and Product Differentiation," Regional Science and Urban Economics, 33(1), 93-113.

Brandenburger, A. and H. Stuart, 2007, "Biform game," Management Science 53(4), 537-549.

Brekke, K.R., R. Nuscheler, and O.R. Straume, 2006, "Quality and Location Choices under Price Regulation," Journal of Economics and Management Strategy, 15(1), 207-227.

Casado-Izaga, F.J., 2000, "Location Decisions: The Role of Uncertainty about Consumer Tastes," Journal of Economics, 71(1), 31-46.

Choi, J.P., 2001, "Technology Transfer with Moral Hazard," International Journal of Industrial Organization, 19(1-2), 249-266.

Cremer, H., M. Marchand, and J.-F. Thisse, 1991, "Mixed Oligopoly with Differentiated Products," International Journal of Industrial Organization, 9(1), 43-53.

d'Aspremont, C., J.-J. Gabszewicz, and J.-F. Thisse, 1979, "On Hotelling's Stability in Competition," Econometrica, 47(5), 1145-1150.

Economides, N., 1986, "Minimal and Maximal Product Differentiation in Hotelling's Duopoly," Economics Letters, 21(1), 121-126.

Faulí-Oller, R., J. Sandonís, 2002, "Welfare Reducing Licensing," Games and Economic Behavior, 41(2), 192-205.

Filippini, L., 2005, "Licensing Contract in a Stackelberg Model," The Manchester School, $73(5), 582-598$. 
Gallini, N.T., B.D. Wright, 1990, "Technology Transfer under Asymmetric Information," RAND Journal of Economics, 21(1), 147-160.

Ganuza, J.-J. and E. Hauk, 2006, "Allocating Ideas: Horizontal Competition in Tournaments," Journal of Economics and Management Strategy, 15(3), 763-787.

Guo, L., 2006, "Consumption Flexibility, Product Configuration, and Market Competition," Marketing Science 25(2), 116-130.

Hauser, J.R. and S.M. Shugan, 1983, "Defensive Marketing Strategies," Marketing Science, 2(4), 319-360.

Hotelling, H., 1929, "Stability in Competition," Economic Journal, 39(153), 41-57.

Kabiraj, T., 2004, "Patent Licensing in a Leadership Structure," The Manchester School, $72(2), 188-205$.

Kamien, M.I., Y. Tauman, 1984, "The Private Value of a Patent: A Game Theoretic Analysis," Journal of Economics, Supplement 4, 93-118.

Kamien, M.I., Y. Tauman, 1986, "Fees versus Royalties and the Private Value of a Patent," Quarterly Journal of Economics, 101(3), 471-491.

Kamien, M. I. and Y. Tauman, 2002, "Patent Licensing: The Inside Story," Manchester School, 70(1), 7-15

Kim, H. and K. Serfes, 2006, "A Location Model with Preference for Variety," Journal of Industrial Economics, 54(4), 569-595.

Katz, M.L., C. Shapiro, 1985, "On the Licensing of Innovations," RAND Journal of Economics, 16(4), 504-520.

Katz, M.L., C. Shapiro, 1986, "How to License Intangible Property," Quarterly Journal of Economics, 101(3), 567-589.

Kotler, P., 1999, Marketing Management: The Millennium Edition. Prentice-Hall: Upper Saddle River, NJ.

Marjit, S., 1990, "On a Non-Cooperative Theory of Technology Transfer," Economics Letters, 33(3), 293-298.

Matsumura, T. and N. Matsushima, 2004, "Endogenous Cost Differentials between Public and Private Enterprises: A Mixed Duopoly Approach," Economica, 71(284), 671-688. 
Matsumura, T., N. Matsushima, and G. Stamatopoulos, 2010, "Location Equilibrium with Asymmetric Firms: The Role of Licensing," Journal of Economics, 99(3), 267-276.

Meagher, K.J. and K.G. Zauner, 2004, "Product Differentiation and Location Decisions under Demand Uncertainty," Journal of Economic Theory, 117(2), 201-216.

Meza, S. and M. Tombak, 2009, "Endogenous Location Leadership," International Journal of Industrial Organization, 27(6), 687-707.

Mukherjee, A., 2001, "Technology Transfer with commitment," Economic Theory, 17(2), 345369.

Muto, S., 1993, "On Licensing Policies in Bertrand Competition," Games and Economic Behavior, 5(2), 257-267.

Neven, D., 1985, "Two Stage (Perfect) Equilibrium in Hotelling's Model," Journal of Industrial Economics, 33(3), 317-325.

Neven, D., 1986, "On Hotelling's Competition with Non-Uniform Customer Distributions," Economics Letters, 21(2), 121-126.

Neven, D., 1987, "Endogenous Sequential Entry in a Spatial Model," International Journal of Industrial Organization, 5(4), 419-434.

Porter, M. E., 1980. Competitive Strategy. Free Press: New York.

Prescott, E.C. and M. Visscher, 1977, "Sequential Location among Firms with Foresight," Bell Journal of Economics, 8(2), 378-393.

Sayman, S., S.J. Hoch, and J.S. Raju, 2002, "Positioning of Store Brands," Marketing Science, 21(4), 378-397.

Saracho, A.I., 2002, "Patent Licensing under Strategic Delegation," Journal of Economics and Management Strategy, 11(2), 225-251.

Sen, D., 2005, "Fee versus Royalty Re-Considered," Games and Economic Behavior, 53(1), $141-147$.

Sen, D., Y. Tauman, 2007, "General Licensing Schemes for a Cost-Reducing Innovation," Games and Economic Behavior, 59(1), 163-186.

Shapiro, C., 1985, "Patent Licensing and R\&D Rivalry," American Economic Review, Papers and Proceedings, 75(2), 25-30. 
Tabuchi, T. and J.-F. Thisse, 1995, "Asymmetric Equilibria in Spatial Competition," International Journal of Industrial Organization, 13(2), 213-227.

Tyagi, R., 2000, "Sequential Product Positioning under Differential Costs," Management Science, 46(7), 928-940.

Vandenbosch, M.B. and C.B. Weinberg, 1995, "Product and Price Competition in a TwoDimensional Vertical Differentiation Model," Marketing Science, 14(2), 224-249.

Wang, X.H., 1998, "Fee versus Royalty Licensing in a Cournot Duopoly Model," Economics Letters, 60(1), 55-62.

Ziss, S., 1993, "Entry Deterrence, Cost Advantage and Horizontal Product Differentiation," Regional Science and Urban Economics, 23(4), 523-543. 